\title{
SCAR MARKER DEVELOPMENT FOR THE CORRECT IDENTIFICATION OF IRIS ENSATA
}

\author{
MOHD. MUGHEES ${ }^{a}$, SHIPRA RANI JHA ${ }^{b}$, JAVED AHMAD ${ }^{b}$, ALTAF AHMAD $^{*}$
}

aDepartment of Biotechnology, School of Chemical and Life Sciences, Jamia Hamdard, New Delhi 110062, India, bDepartment of Botany, School of Chemical and Life Sciences, Jamia Hamdard, New Delhi 110062, India, 'Department of Botany, Aligarh Muslim University, Aligarh 202001, India

Email: aahmad.bo@amu.ac.in

Received: 28 Jul 2017 Revised and Accepted: 02 Nov 2017

ABSTRACT

Objective: The objective of this research was to develop the RAPD based SCAR marker for the correct identification of the Iris ensata Thunb. (I. ensata) plant from its adulterants.

Methods: Five samples of I. ensata. from the different geographical area were used in this study. The plant genomic DNA was isolated with the CTAB method with some modification (as dried samples were also used). After that, polymorphism was checked with the help of the 10-mer random primers of OPAA and BG series. Then, the bands of interest were eluted and cloned into pGEMT easy vector for the sequencing. Finally, the sequence is used to develop the SCAR primers (Ir-f andIr-R) specific for I. ensata and the developed primers also validated with respect to the market samples.

Results: A putative 580 bp sequence specific for Iris ensata was identified from the randomly amplified polymorphic DNA (RAPD) analysis. To overcome the main limitation of RAPD it has been converted into SCAR markers. So that, this specific band was then eluted, cloned and sequenced. After that, SCAR primers (Ir-F and Ir-R) were synthesized by using this sequence. For the validation of the synthesized SCAR primers, they were tested with respect to the market samples. The amplicon of $260 \mathrm{bp}$ was produced by the SCAR primers in the authentic I. ensata but market samples did not produce any bands with the synthesized SCAR primers.

Conclusion: The results of this study show a high level of polymorphism in the RAPD pattern of the different accessions of the plant. Furthermore, this study results in the successful development of the RAPD based SCAR marker for the identification of the I. ensata.

Keywords: Herbal, Iris, Medicinal plant, RAPD, SCAR

(C) 2017 The Authors. Published by Innovare Academic Sciences Pvt Ltd. This is an open-access article under the CC BY license (http://creativecommons.org/licenses/by/4.0/) DOI: http://dx.doi.org/10.22159/ijpps.2017v9i12.21677

\section{INTRODUCTION}

In Iridaceae family, Iris is the major genus which has near about 230 species [1]. It provides models for the introgressive hybridization and hybrid fitness studies of the plant [2]. The plant is mainly found in China, Japan, Korea, and Russia [1]. The I. ensata species of Iris is one of the generally cultured, crossbred, and imperative horticultural species [3] and has several essential conjoint cultivars recognized as 'Japanese Iris.' 'Hanashobu' (Japanese common name).

The roots of the plant have many important medicinal properties like it is used to kill parasitic worms, used in hepatic diseases, used as an appetizer, as a diuretic agent, as a detoxifying agent and as an antidote [4-6]. This plant is also used in combination with other plants to treat various diseases such as liver grievances, dropsy and venereal affections [7].

Molecular biology provides various techniques that can be useful for plant identification from their adulterant [8]. At the genetic level, polymorphism has been broadly studied in medicinal plants which help in distinguishing plants at inter or intraspecies level [9-10]. DNA-based molecular markers can be used in the enhancement of medicinal plant species. These markers can be used for evaluating genetic diversity in plants, authenticating plant material from their adulterants thereby utilizing them for MAS breeding and therapeutics. From the last two decades, the PCR (Polymerase Chain Reaction) became one of the main methods for the nucleic acid analyses [11]. PCR based markers including Randomly Amplified Polymorphic DNA (RAPD) can be proficiently used for verification of the medicinal plant material [12].

Furthermore, RAPD marker also has been used to study the genetic variations among the geologically different population of fungi [13]. In herbal medicine, RAPD analysis has been used to differentiate between species in numerous genera [14]. The necessity of small amounts of plant material, quickness and low cost are the advantages of RAPD [14-
15]. RAPD reveals a high degree of polymorphism without the requirement of prior DNA sequence information and it is simple to perform. The RAPD technique amplified unique fragments as this technique does not amplify two discrete fragments that co-migrate on gels having a similar size [16]. Therefore, this application is explored by various researchers for authentication of traditional medicinal plants [17]. Reproducibility of the RAPD results is low because this technique is sensitive to PCR conditions. To prevail over this problem, RAPD has to be converted into sequence characterized amplified region (SCAR) marker [18]. Further, industrial application of the molecular techniques can be increased by the development of more specific, sensitive and reproducible markers like Sequence Characterized Amplified Region (SCAR). In the present study, we developed reliable SCAR markers based on the amplified product of the RAPD primers for the identification of Iris ensata from its adulterants.

\section{MATERIALS AND METHODS}

\section{Plant material}

Five different accessions of I. ensata were used in this study. Roots and aerial parts of five different accessions were collected from different geographical areas of India (table 1). These samples were identified by Prof. M. P. Sharma, Head, Dept. of Botany, Jamia Hamdard, voucher specimen is deposited at the herbarium (No. $\mathrm{DM} / \mathrm{JH} / 251-\mathrm{a} / 2013-1, \quad \mathrm{DM} / \mathrm{JH} / 251-\mathrm{b} / 2013-14, \quad \mathrm{DM} / \mathrm{JH} / 251-\mathrm{c} /$ 2013-14， DM/JH/251-d/2013-14, DM/JH/251-e/2013-14) of Department of Botany, Jamia Hamdard, New Delhi. For the validation of marker two market samples of the plant were also collected from the local herb market of Khari Baoli, Delhi, India.

Chemicals

All chemicals used in the study were molecular grade. EDTA (Ethylenediaminetetraacetic acid), CTAB (Cetyl Trimethyl 
Ammonium Bromide), NaCl, Tris HCL, Agarose, $\beta$-mercaptoethanol, Phenol, Chloroform, Isoamyl alcohol, Ammonium acetate were purchased from Hi-media, Mumbai, India. The RAPD primers, PCR reaction mixture, and RNase were purchased from Merck (Darmstadt, Germany), whereas the developed primers (SCAR) were purchased from IDT, USA.

Table 1: List of plant materials (I. ensata) used in this study

\begin{tabular}{llll}
\hline Plant name & Plant part & Sample & Locality \\
\hline I. ensata & Aerial & Ir-1 & IHBT, Palampur \\
& Aerial & Ir-2 & University of Kashmir, Srinagar \\
& Root & Ir-3 & Chopta forest, Himalayas \\
& Root & Ir-4 & Chamba, Himachal Pradesh \\
& Root & Ir-5 & Hamdard laboratory, Ghaziabad \\
\hline
\end{tabular}

\section{Genomic DNA isolation}

\section{Sample preparation}

Dried root samples of Iris ensata were chopped into small pieces and kept overnight in distilled water to make them soft then these roots samples were pressed to remove excess water and these soft roots were used for genomic DNA isolation.

\section{DNA extraction}

Genomic DNA of root sample of I. ensata was isolated by CTAB extraction method [19] with some modifications. $4.0 \mathrm{~g}$ of root sample was ground in liquid nitrogen to a fine powder. $15 \mathrm{ml}$ of prewarmed $\left(65^{\circ} \mathrm{C}\right) 4 \mathrm{x}$ CTAB buffer [4\% CTAB, $1.4 \mathrm{M} \mathrm{NaCl}, 0.5 \mathrm{M}$ EDTA (18.61 gm/100 ml) pH-8, 0.5 M Tris-HCl (15.76 gm/100 ml) pH-8] and $0.2 \% \quad \beta$-mercaptoethanol was added just before use. The homogenate was incubated at $65^{\circ} \mathrm{C}$ in a water bath for $45 \mathrm{~min}$ with intermittent mixing. An equal volume of Phenol: Chloroform: Isoamyl alcohol (25:24:1) was added and mixed well by inverting the tubes 3-4 times. The suspension was then centrifuged twice at $10000 \mathrm{rpm}$ for $15 \mathrm{~min}$ at $25^{\circ} \mathrm{C}$. The aqueous phase was transferred to a fresh tube and $5 \mu \mathrm{L}$ of RNase $(50 \mathrm{mg} / \mathrm{ml})$ was added to the aqueous phase and incubated at $37{ }^{\circ} \mathrm{C}$ for 1 hour. The aqueous phase was extracted again by adding an equal volume of Chloroform/Iso amyl alcohol (24:1). The suspension was mixed well and then centrifuged for $15 \mathrm{~min}$ at $4{ }^{\circ} \mathrm{C}$ at $10000 \mathrm{rpm}$. The aqueous phase was again transferred to a fresh tube. One volume of chilled Isopropanol was added to the aqueous phase and incubated at-20 ${ }^{\circ} \mathrm{C}$ for overnight for precipitation of DNA. The DNA was pelleted by centrifugation at $10000 \mathrm{rpm}$ for $15 \mathrm{~min}$ at $4{ }^{\circ} \mathrm{C}$. DNA pellet was then washed with washing solution (70\% ethanol, $2 \mathrm{M}$ ammonium acetate) and air dried. The pellet was dissolved in an appropriate volume (200-300 $\mu \mathrm{L})$ of TE buffer or sterile Milli-Q water. The DNA solution was stored at $4{ }^{\circ} \mathrm{C}$ for immediate use or at-20 ${ }^{\circ} \mathrm{C}$ for prolonged storage.

\section{RAPD analysis}

A set of 40 random primers of OPAA and BG series was used for the PCR screening of genomic DNA of all five accessions of $I$. ensata (table 2). Ten primers showing clear and reproducible polymorphic patterns in preliminary trials were selected to analyze the further RAPD. PCR reactions were carried out in the $15 \mu$ reaction volume containing $(5 \mathrm{U} \mu \mathrm{l}) \mathrm{Taq}$ polymerase, $1 \mathrm{x}$ Taq buffer $(10 \mathrm{mmol}), \mathrm{MgCl}_{2}$ (10 mmol), dNTPs (2.5 mmol each), $10 \mu \mathrm{M}$ of each primer and 50 $\mathrm{ng} / \mu \mathrm{l}$ of DNA template. Amplification was performed in a thermal cycler (T100 TM Thermal Cycler, Bio-Rad, USA).

PCR conditions were set as: initial denaturation $95{ }^{\circ} \mathrm{C}$ for $4 \mathrm{~min}$, denaturation at $94{ }^{\circ} \mathrm{C}$ for $30 \mathrm{sec}$, annealing at $32{ }^{\circ} \mathrm{C}$ for $45 \mathrm{sec}$, extension at $72{ }^{\circ} \mathrm{C}$ for $50 \mathrm{sec}$, and a final extension at $72{ }^{\circ} \mathrm{C}$ for $2 \mathrm{~min}$ and infinite hold on $4{ }^{\circ} \mathrm{C}$. Amplified PCR products $(15 \mu \mathrm{l})$ along with $3 \mu \mathrm{l} 6 \mathrm{X}$ bromophenol dye were loaded on $1-1.2 \%$ agarose gel containing ethidium bromide $(0.5 \mu \mathrm{g} / \mathrm{ml})$ prepared in $1 \mathrm{X}$ TAE buffer and electrophoresed on 100 volts for one and half hour. The amplified DNA was visualized on UV lamp and photographed under UV light using gel documentation system (Alphalmager EC, USA).

Table 2: Nucleotide sequences of selected primers with the number of amplified products and fragment size range (bp)

\begin{tabular}{|c|c|c|c|}
\hline Primer code & Primer sequence $\left(5^{\prime}-3^{\prime}\right)$ & No. of amplified products & Fragment size \\
\hline OPAA-01 & CCGGCCCTTC & 30 & $200-1000$ \\
\hline OPAA-02 & TGCCGAGCTG & 35 & $310-800$ \\
\hline OPAA-05 & AGGGGTCTTG & 32 & $215-750$ \\
\hline OPAA-07 & GAAACGGGTG & 40 & $300-830$ \\
\hline OPAA-08 & GTGACGTAGG & 37 & $210-800$ \\
\hline OPAA-11 & CAATCGCCGT & 55 & $400-1500$ \\
\hline OPAA-15 & TTCCGAACCC & 42 & $430-1200$ \\
\hline OPAA-17 & GACCGCTTGT & 34 & $350-930$ \\
\hline OPAA-19 & CAAACGTCGG & 41 & $250-735$ \\
\hline OPAA-20 & GTTGCGATCC & 29 & $435-1025$ \\
\hline BG-26 & AAGCCTCGTC & 30 & $380-900$ \\
\hline BG-27 & TGCGTGCTTG & 34 & $290-965$ \\
\hline BG-28 & GACGGATCAG & 41 & $400-1240$ \\
\hline BG-29 & CACACTCCAG & 38 & $410-1325$ \\
\hline $\mathrm{BG}-30$ & TGAGTGGGTG & 30 & $340-950$ \\
\hline
\end{tabular}

\section{Cloning and sequencing of the polymorphic band}

The putative marker amplified by the random primer OPAA-11 was eluted from $1.2 \%$ agarose gel with sterile gel slicer and purified by using Gel Extraction Kit (Nucleopore-Genetix). The sliced amplicon was cloned using the pGEM-T easy vector I (Promega, USA). The ligated plasmid was introduced into Escherichia coli strain $\mathrm{DH}_{10 \mathrm{~B}}$, following the protocols for preparing competent cells and transformation using the calcium chloride method [20]. White colonies were picked from LB/ampicillin/X-gal/IPTG plates and grown overnight in LB medium. The plasmid DNA was isolated from the bacterial culture using plasmid isolation kit (RBC Real Genomics ${ }^{\mathrm{TM}}$, Taiwan). The inserted fragment was sequenced at Ist Base sequencing, Singapore with SP6 and T7 primer. The nucleotide sequence of $580 \mathrm{bp}$ RAPD amplicon, specific for all the five accessions of $I$. ensata were used for designing primers for development of SCAR marker. 
Table 3: Details of the I. ensata specific SCAR marker designed from the 580-bp polymorphic sequence

\begin{tabular}{|c|c|c|c|c|c|}
\hline $\begin{array}{l}\text { Name of random } \\
\text { decamer primer used }\end{array}$ & $\begin{array}{l}\text { Sequence of random } \\
\text { decamer primer }\left(5^{\prime}-3^{\prime}\right)\end{array}$ & $\begin{array}{l}\text { Name of the } \\
\text { SCAR primer }\end{array}$ & $\begin{array}{l}\text { Sequence of the SCAR } \\
\text { primer }\left(5^{\prime}-3^{\prime}\right)\end{array}$ & $\begin{array}{l}\text { G+C content } \\
(\%)\end{array}$ & $\begin{array}{l}\text { Annealing } \\
\text { temperature }\left({ }^{\circ} \mathrm{C}\right)\end{array}$ \\
\hline OPAA-11 & CAATCGCCGT & $\begin{array}{l}\text { Ir-F } \\
\text { Ir-R }\end{array}$ & $\begin{array}{l}\text { AGAGGGGGCCAAGAAGAATA } \\
\text { TTCAACACGCGAAGTTATCG }\end{array}$ & $\begin{array}{l}50.0 \\
45.0\end{array}$ & $\begin{array}{l}58^{\circ} \mathrm{C} \\
58^{\circ} \mathrm{C}\end{array}$ \\
\hline
\end{tabular}

\section{SCAR primers designing and validation}

Based on the sequence of unique RAPD amplicon a pair of $20 \mathrm{bp}$ oligonucleotide primers (Ir-F and Ir-R), defining a SCAR for each of the cloned fragments was designed and synthesized for specific amplification of the loci identified by the RAPD markers (table 3). PCR reactions were carried out in the $15 \mu \mathrm{l}$ reaction volume containing (5U $\mu \mathrm{l}) \mathrm{Taq}$ polymerase, $1 \mathrm{X}$ Taq buffer, $(10 \mathrm{mmol}) \mathrm{MgCl}^{2}, 10 \mathrm{mmol}$ dNTPs (2.5 mmol each), $10 \mu \mathrm{M}$ of each primer (SCAR-forward and SCARreverse) and $50 \mathrm{ng} / \mu \mathrm{l}$ of DNA template. Amplification was performed in a thermal cycler (T100 TM Thermal Cycler, Bio-Rad, USA). PCR conditions were set as: initial denaturation $95{ }^{\circ} \mathrm{C}$ for $4 \mathrm{~min}$, denaturation at $94{ }^{\circ} \mathrm{C}$ for $30 \mathrm{sec}$, annealing at $58{ }^{\circ} \mathrm{C}$ for $45 \mathrm{sec}$, extension at $72{ }^{\circ} \mathrm{C}$ for $50 \mathrm{sec}$, and a final extension at $72{ }^{\circ} \mathrm{C}$ for $2 \mathrm{~min}$ and infinite hold on $4{ }^{\circ} \mathrm{C}$. Amplified SCAR product along with $2 \mu \mathrm{l} 6 \mathrm{X}$ bromophenol dye was loaded on $1-1.2 \%$ agarose gel containing ethidium bromide $(0.5 \mu \mathrm{g} / \mathrm{ml})$ prepared in $1 \mathrm{X}$ TAE buffer and electrophoresed on 100 volts for one and half hour. The amplified product was visualized on UV lamp and photographed under UV light using gel documentation system Alphalmager EC (USA).

DNA was also isolated from commercial crude drug samples of $I$. ensata using the above isolation method. The isolated DNA samples were then put to test with the above SCAR primers for validation.

\section{RESULTS}

\section{DNA extraction and RAPD}

High molecular weight genomic DNA was isolated from the dried plant samples. The DNA extraction procedure yielded 600-800 ng of DNA per $100 \mathrm{mg}$ of tissue. First, the isolated genomic DNA showed the absorbance (A260/A280 ratio) of 1.6-1.7 that indicated the contamination of proteins and polysaccharides. This contamination was removed by the Phenol: Chloroform: Iso-amyl Alcohol (25:24:1) treatment which results in the absorbance (A260/A280 ratio) of genomic DNA to the 1.7-1.8 which was highly purified.

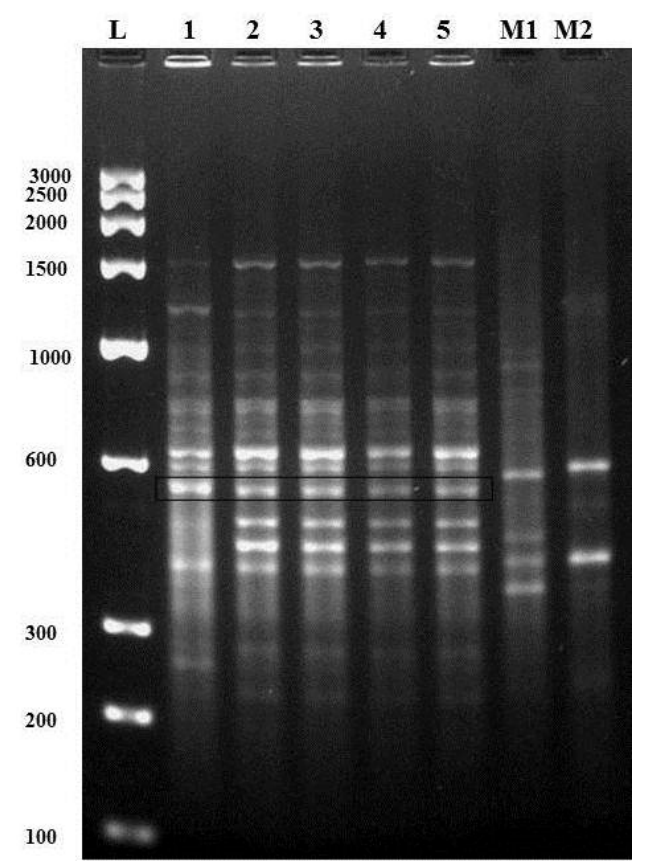

Fig. 1: RAPD pattern with OPAA-11, L-Low range DNA ladder,1-5 DNA Samples of I. ensata, M1-M2-Market sample
40 RAPD 10-mer primers were used for screening of all the accessions of the genuine plant (I. ensata) and its adulterants. Primers (OPAA 01, OPAA 02, OPAA 05, OPAA 07, OPAA 08, OPAA 11, OPAA 15, OPAA 17, OPAA 19, OPAA 20, BG-26, BG-27, BG-28, BG-29, BG-30) produced good quality, reproducible fingerprint patterns and showed a high level of consistency.

The total of 525 DNA fragments of 200-1500 bp was obtained. To confirm the reproducibility of RAPD pattern the experiment was carried out three times with same conditions, the same composition of reaction volume and a thermal cycler. Primer OPAA-11 consistently amplified an intense $580 \mathrm{bp}$ band that was unique to all the accessions of $I$. ensata. This $580 \mathrm{bp}$ amplicon was not observed in the market samples of I. ensata tested. (fig. 1).

\section{Cloning and sequencing of polymorphic band}

A polymorphic band (580bp) that was specific in all the accessions of $I$. ensata but absent in its adulterants was selected. This specific band was eluted, cloned and sequenced. Restriction digestion from the EcoR 1 and Spe 1 enzymes revealed 580 bp band on $1.2 \%$ agarose gel that confirmed the presence of the insert of the desired gene in the vector. The sequencing of this recombinant construct was done by using SP6 and T7 primers.

1

TTTGGCCTTCTCAGATCGTCTATGTGTTCGCGCAGGCCCTGGCCCTCAGG GGGAACATAT

61

TTCTCACCCTCCTTCGGCAGGATAAAGTTCATCTCCACGAAGTGACGCA GGTCAAAACCG

121

GACAGGGTATGCTGCATCCGGTAATCCGCCAGGATCATCAGCGGGTCGC TTTTGGGAACG

181

GCATCCGCGAAGGTTTTCTGATCCGGGAACAGTTTGGCGCTCTGAACGT CATTAAAGAGG

241

GGGCCAAGAAGAATATCAGGTGAGCTTTGCTGGCTCGTTGGCTGGTCT TCAGCATAACCA

301

AATGCGGTAACACCGAGTAGTGCGCCTGCCAACGCAAGGGGTAAAAAA GCGGGGCGTCGT

361

GCGCGAGGTCTTATCATCGGTTCGTCTCCTGTCTTCACTGAGCAGCGTG ACCGCTGTTGT

421

CAATTACCTGAAAACCTTAGACAAATATCGATAACTTCGCGTGTTGAA TGTCCCATTTTT

481

CGCATAACCAGATAATTCGGGTGCGCTTTCACTACACCAGGGTTGGATT ACTTAATTTTT

541

AACCACACCTCGGAAAGGCCGGGTAAGCTTCATGCCACCCGGCTTAAGC CCTACAACCCT

601

TTATTATCCATCAGCACCGCCAAATCCACCAGACGATCTGAGAAGGCCA AAA

\section{Validation of SCAR primers}

The genomic DNA of all the accessions of I. ensata and of the market samples were amplified by the SCAR primers (Ir-F and Ir-R) for the 
applicability of the SCAR marker for the molecular authentication of the plant. A single, bright and distinct band of $260 \mathrm{bp}$ was obtained only from the genomic DNA of the authenticated accessions of the $I$. ensata and no amplification product was obtained from the genomic DNA of the market samples of I. ensata (fig. 2). This confirms the specificity and the sensitivity of the SCAR marker for the I. ensata. Further, this result confirms that these SCAR markers can be used for the molecular identification of I. ensata.

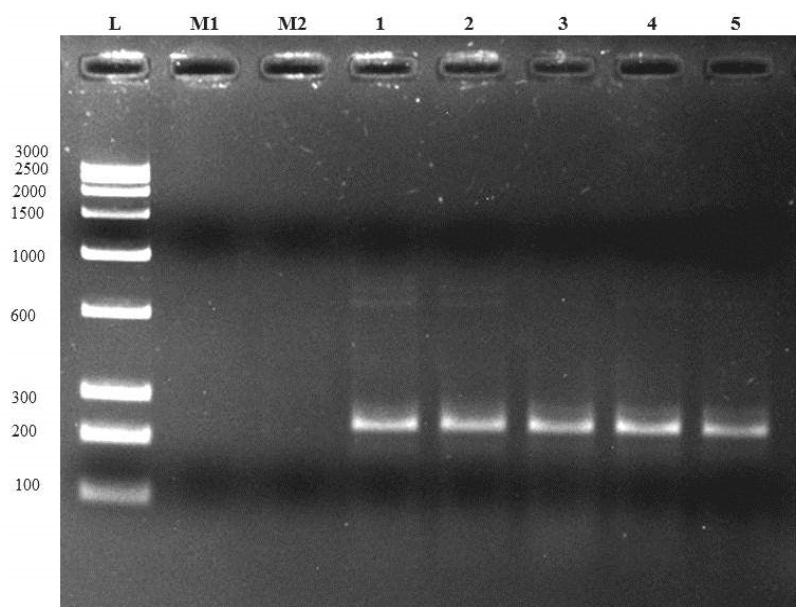

Fig. 2: PCR amplification of I. ensata and market sample with SCAR (Ir-F andIr-R) primers, L-DNA Marker, M1-M2-Market sample,1-5 DNA Samples of I. Ensata

\section{DISCUSSION}

In this study, we developed the RAPD based SCAR marker for the identification of the I. ensata. For the development of SCAR marker, we used five accessions of the plant as it is the high altitude plant and has very low availability. However, many published studies showed the development of RAPD based marker from the large number of accessions but these plants have good availability such as genus Artemisia [21], Panax species [22], Phyllanthus species [23], Ganoderma lucidum [24], Ipomoea mauritiana [25], Bemisiatabaci (Genn.) [26]. additionally, in our study, we used dried root samples for the isolation of the genomic DNA and we successfully isolated the ample amount of genomic DNA by doing some modifications in the CTAB method of Doyle and Doyle (1990). Thus, establishing a reliable DNA fingerprinting for the dried samples of the I. ensata is very significant for SCAR analysis. In our RAPD analysis, significant genetic polymorphism was observed among $I$. ensata and its adulterants. The SCAR primers designed using this sequence variation was found to be specific for I. ensata making the technique more stringent and specific as compared with RAPD marker.

However, at the molecular level, there are few studies that have been reported for the different species of Iris [27-28]. By using RAPD, genetic diversity has been analyzed amongst different species of Iris [27]. Based upon a study on Iris species, the phylogeny of the genus Iris has been reported to be based on matK gene and trnK intron sequence data [29]. Yue-E-Xiao et al. (2012) developed 13 polymorphic microsatellite loci in I. ensata exhibited a large number of alleles per locus and high heterozygosity [29]. Although, some work has been reported on the genus Iris at the molecular level, but very few on Iris ensata. As we discussed earlier our study provide an easy and cheaper way of identification of I. ensata from their adulterants, as RAPD based SCAR marker is easy to develop and it is economically sound too.

\section{CONCLUSION}

In the present study, RAPD based sequence characterized amplified regions (SCAR) marker of Iris ensata Thunb. The plant was successfully developed, which is more accurate than RAPD markers. Therefore, the SCAR markers (Ir-F and Ir-R) developed in the present study could be of immense use for the identification of Iris ensata Thunb. a medicinally important plant.

\section{AUTHOR'S CONTRIBUTION}

MM performed all the experiments of the manuscript and wrote the manuscript. SRJ assisted MM in the experiments as well as in the writing the manuscript. AA and JA were instrumental in helping the students in carrying out this work and final proofreading of this manuscript was also done by them. The working concept was designed by AA.

\section{ACKNOWLEDGMENT}

The authors are grateful to University Grants Commission (UGC) for financial assistance for the study and Honourable Vice-chancellor of Jamia Hamdard (Hamdard University) for providing the necessary facilities for the study.

\section{CONFLICT OF INTERESTS}

\section{Declared none}

\section{REFERENCES}

1. Zhao Y, Noltie HJ, Mathew B. Iridaceae. In: Wu ZY, Raven PH. eds. Flora of China, Vol. 24. Science Press: Beijing and Missouri Botanical Garden Press, St. Louis; 2000. p. 297-313.

2. Arnold ML, Ballerini E, Brothers AN. Hybrid fitness, adaptation and evolutionary diversification: Lessons learned from Louisiana irises. Heredity 2012;108:159-66.

3. Mcewen C. The Japanese Iris. Brandeis University Press: Waltham, Massachusetts, USA; 1990.

4. Usher GA. Dictionary of Plants Used by Man. Constable Press: London; 1974.

5. Stuart GA. Rev Chinese Materia Medica. Chinese Materia Medica: Vegetable Kingdom By Rev GA, Stuart MD. American Presbyterian Mission Press: Shanghai; 1911.

6. Duke JA, Ayensu ES. Medicinal plants of China Strichzeichnungen. Reference Publ, Inc Algonac Michigan; 2008;2:705S, 1300.

7. Chopra RN, Nayar SL, Chopra IC, Asolkar LV, Kakkar KK, Chakre OJ, et al. Glossary of Indian Medicinal Plants (Including the Supplement). Council of Scientific and Industrial Research (India); 2008.

8. Techen N, Crockett SL, Khan IA, Scheffler BE. Authentication of medicinal plants using molecular biology techniques to compliment conventional methods. Curr Med Chem 2004;11:1391-401.

9. Joshi K, Chavan P, Warude D, Patwardhan B. Molecular markers in herbal drug technology. Curr Sci 2004;87:157-65.

10. Weder JK. Identification of plant food raw material by RAPDPCR: legumes. J Agric Food Chem 2002;50:4456-63.

11. Ali AM, Gandhi SV, Malla S. Development of multiplex PCR based assay for the concurrent detection of pathogenic microorganisms. Int J Curr Pharm Res 2015;7:83-5.

12. Williams JGK, Kubelik AR, Livak KJ, Rafalski JA, Tingey SV. DNA polymorphisms amplified by arbitrary primers are useful as genetic markers. Nucleic Acids Res 1990;18:6531-5.

13. Thilagavathi T, Kathiravan G. Isolation of taxol-producing fusicoccum species from curry leaf and its random amplified polymorphic DNA analysis. Asian J Pharm Clin Res 2016;9:202-5.

14. Shcher NJ, Carles MC. Genome-based approaches to the authentication of medicinal plants. Planta Medica 2008;74:603-23.

15. Penner GA, Bush A, Wise R, Kim W, Domier L, Kasha K, et al. Reproducibility of random amplified DNA (RAPD) analysis among laboratories. PCR Methods Applications 1993;2:341-5.

16. Sikkandar S, Murugan K, Nair A, Tilton F. Molecular authentication and genetic diversity analysis of Haloferox volcanii and Halobacterium salinarium from salt brines. Asian J Pharm Clin Res 2013;6:158-60.

17. Dyaneshwar W, Preethi C, Kalpana J, Bhushan P. Development and application of RAPD-SCAR marker for identification of Phyllanthus emblica LINN. Biol Pharm Bull 2006;29:2313-6.

18. Paran I, Michelmore R. Development of reliable PCR-based markers linked to downy mildew resistance genes in lettuce. Theor Appl Genet 1993;85:985-93. 
19. Doyle JJ, Doyle JL. Isolation of plant DNA from fresh tissue. Focus 1990;12:13-5.

20. Saad B, Azaizeh H, Abu HG, Said O. Safety of traditional Arab herbal medicine. Evidence-Based Complementary Med 2006;3:433-9.

21. Lee MY, Doh EJ, Park $\mathrm{CH}$, Kim YH, Kim ES, Ko BS, et al Development of SCAR marker for discrimination of Artemisia princeps and $A$. argyifrom other Artemisia herbs. Biol Pharm Bull 2006;29:629-33.

22. Wang J, Ha WY, Ngan FN, But PP, Shaw PC. Application of sequence characterized amplified region (SCAR) analysis to authenticate Panax species and their adulterants. Planta Med 2001;67:781-3.

23. Dyaneshwar W, Preethi C, Kalpana J, Bhushan P. Development and application of RAPD-SCAR marker for identification of Phyllanthusemblica LINN. Biol Pharm Bull 2006;29:2313-6.

24. Su H, Wang J, Ge Y, Feng E, Sun J, Liu L. Development of strainspecific SCAR markers for authentication of Ganoderma lucidum. World J Microbiol Biotechnol 2008;24:1223-6.
25. Devaiah $\mathrm{K}$, Balasubramani SP, Venkatasubramanian $\mathrm{P}$. Development of randomly amplified polymorphic DNA based SCAR marker for identification of Ipomoea mauritianaJacq (Convolvulaceae). Evidence-Based Complementary Alternative Med 2011;1-7. Doi:10.1093/ecam/neq023

26. Gupta VK, Sharma R, Jindal V, Dilawari VK. SCAR marker for identification of host plant specificity in whitefly Bemisiatabaci (Genn.). Indian J Biotechnol 2010;9:360-6.

27. Al-Gabbiesh AH, Hassawi DS, Afifi FU. Determination of genetic diversity among Iris species using random amplified polymorphic DNA analysis. Biotechnology 2006;5:173-9.

28. Wilson CA. Phylogeny of Iris based on chloroplast matK gene and trnK intron sequence data. Mol Phylogenet Evol 2004;33:402-12.

29. XiaoYE, Hu YH, Liu M, Chen XY. Isolation and characterization of polymorphic microsatellites in Iris ensata (Iridaceae). Am J Bot 2012;99:e498-500. 